\title{
Softening and Hardening of ECAP Nickel under Ultrasonic Treatment
}

A.P. Zhilyaev ${ }^{1,2^{*}}$, A.A. Samigullina ${ }^{1}$, A.E. Medvedeva ${ }^{1,3}$, S.N. Sergeev ${ }^{1}$, J.M. Cabrera ${ }^{4}$, A.A. Nazarov ${ }^{1}$

${ }^{1}$ Institute for Metals Superplasticity Problems of the Russian Academy of Sciences, 39

Khalturina, Ufa, 450001 Russia

${ }^{2}$ Fundació CTM Centre Tecnològic, Plaça de la Ciencia 2, Manresa, Barcelona, 08242 Spain

${ }^{3}$ Ufa State Aviation Technical University, 12 K. Marx str., Ufa, 450000 Russia

${ }^{4}$ Departamento de Ciencia de los Materiales e Ingeniería Metalúrgica, EEBE - Universitat

Politècnica de Catalunya, c/ Eduard Maristany 10-14, Barcelona, 08019 Spain

*Corresponding author, e-mail: AlexZ@anrb.ru

\section{Abstract.}

Commercially pure nickel was processed by equal channel angular pressing (ECAP) through route $\mathrm{Bc}$ for 12 passes to obtain an ultrafine grained (UFG) microstructure and further subjected to an ultrasonic treatment (UST) which introduced a maximum amplitude equivalent to anormal stresses of $100 \mathrm{MPa}$ in a steady state regime. It was observed that the microstructure of UFG Ni can be differently altered depending on the position in the sample, i.e. on the amplitude of the ultrasonic wave. The microstructural analysis demonstrated a lower dislocation density (due to the activation of recovery) at the cross section of the specimen subjected to UST at an amplitude equal to 0.8 of the maximum one, plus enhanced hardening in the cross section at the maximum amplitude.

Keywords: nickel; equal channel angular pressing (ECAP); ultrasonic treatment; microstructure; softening; hardening

\section{Introduction}

Ultrasonic treatment (UST) of metallic materials has a wide range of applications due to its influence on the structure and properties of materials [1-7]. Interaction of ultrasound waves with grain boundaries, dislocations, and with other crystal lattice defects can lead to changes in their structure and arrangements that determines the microstructure, affects mechanical properties of materials and results in a number of interesting effects [1,2,5]. Well-known consequences of UST are the Blaha-Langenecker effect [8], or the yield or flow stress reduction during constantstrain rate experiments, and the Archbutt effect [9], or the strain rate increase during creep 
experiments in the presence of a superimposed oscillating stress. These softening effects of ultrasound are commonly referred to as acoustoplastic effect. Ultrasonics welding of similar and dissimilar materials has become a successful industrial technology [6,7]; moreover, it provided the fundamental base for the new emerging technology of ultrasonic additive manufacturing [7]. Another example of commercially used technologies of ultrasonic treatment is the surface modification by ultrasonic peening [10-13]. For instance, high-intensity ultrasound affects grain refinement in alloys and even can be used for nanostructuring of surface layers of materials that results in surface hardening [14]. Finally, ultrasounds can also be used to accelerate some reactions in metals, e.g., phase transformation processes in shape memory TiNi alloys $[15,16]$ or grain refinement during solidification [refs].

At the same time, a great attention in the last few decades has been given to bulk nanostructured materials processed by severe plastic deformation (SPD) methods. Metals processed by SPD demonstrate high strength and fatigue properties, enhanced wear resistance, improved superplasticity (at lower temperatures and larger strain rates than conventional superplastic conditions). On the other hand SPD metals display significant distortion of the crystal lattice because the presence of non-equilibrium state grain boundaries $[17,18]$. Internal grain volumes in these materials usually have a highly distorted structure contanining individual lattice dislocations, high-energy structures, large fraction of low-angle subgrain boundaries, etc. The high internal stresses usually present in the structure of such materials result in low ductility, low impact toughness and limited thermal stability of the microstructure [17].

Although, in some cases, ductility can be improved by optimizing the stacking fault energy [19] and the deformation process [20], the main way for its improvement is the relaxation of the non-equilibrium microstructure. Usually the structure of deformed materials can be relaxed by annealing. However, it is accompanied by an undesirable grain growth that significantly reduces the strengthening effect obtained by nanostructuring through SPD [21,22]. Therefore, alternative methods of non-equilibrium structure relaxation in SPD-processed nanomaterials, which would allow one to improve their thermal stability, ductility and impact toughness, are of great interest.

In spite of the wide use of ultrasounds with a large range of frequencies and amplitudes in many fields of materials science and engineering, the influence of ultrasonic vibrations on the non-equilibrium structure of nanostructured materials are not yet well explored. Some mechanisms of the influence of alternating stresses induced by the ultrasonic field on dislocations and their arrays have been described, for example, in [5,23,24], but still such mechanisms are far from being fully understood.

It has been shown in recent works of some of the present authorsthat UST of some moderate intensity imposed on nanostructured nickel processed by high pressure torsion (HPT) 
lead to an increase of the thermal stability of its microstructure [25]. UST of equal-channel angular pressing (ECAP) processed nickel also resulted in a simultaneous increase of ductility, strength and impact toughness [26,27].

Atomistic simulations of the interaction of ultrasonic waves with crystal lattice defects in a two-dimensional nanocrystal has shown as well a number of interesting effects consistent with experimental data, namely, a decrease of the number of low-angle grain boundaries, relaxation of non-equilibrium grain boundaries and triple junctions avoiding grain growth, and annihilation of lattice dislocation [28]. Three-dimensional molecular dynamics simulation studies have displayed that emission of lattice dislocations by nonequilibrium grain boundaries facilitated by their internal stresses can be an underlying atomistic mechanism for the structure relaxation effects of UST in the SPD-processed materials [29, 30].

These promising results need to be understood and studied in more detail and accuracy. In consequence, in the present study was carry out a detailed analysis of the microstructure of nanostructured nickel processed by ECAP and subjected to UST with a maximum stress amplitude of $100 \mathrm{MPa}$. This maximum was chosen on the base of earlier studies [26]. The final aim of the present study is to find the dependence of quantitative characteristics of the microstructure such as the fraction of high-angle boundaries, dislocation density, average grain size, etc., on the amplitude of the ultrasounds applied.

\section{Experimental materials and procedure}

Cylindrical samples of commercially pure nickel (99.5\%, grade NP2 according to Russian classification) were subjected to 12 passes of ECAP following route $\mathrm{B}_{\mathrm{C}}$, i.e. by rotating the sample to $90^{\circ}$ in the same direction around its axis before each subsequent pass [26]. The deformation temperature was set equal to $350^{\circ} \mathrm{C}$. After ECAP, the samples were subjected to a slight extrusion to obtain cylinders of $18 \mathrm{~mm}$ in diameter and $104 \mathrm{~mm}$ in length. The latter size is approximately equal to a half wavelength of an ultrasonic wave at a frequency of $22 \mathrm{kHz}$ in nickel. This made possible to generate a standing ultrasonic wave by along this sample.

The sample and a scheme of the UST applied are depicted in Fig. 1. The left end of the sample is firmly attached to an acoustic transducer, which is powered by and ultrasonic generator producing mechanical vibrations in the sample at frequency of $22 \mathrm{kHz}$. Since the vibrations are transmitted to the half-wavelength sample, a standing wave is formed in the latter and the amplitude of oscillating displacements along the sample obey the relation $\xi=\xi_{0} \sin (\pi x / l)$, where $\xi_{0}$ is the amplitude of displacements of the sample edges, i.e. at $x= \pm l / 2= \pm \lambda / 4, \lambda$ the wave length and $x$ the distance from the centre of the sample. Therefore, the amplitude of normal 
stress at any point of the sample, $A(\bar{x})=E d \xi(x) / d x$, where $E$ is the Young modulus, can be obtained from the following relationship:

$$
A(x)=A_{0} \cos \frac{2 \pi}{\lambda} x,
$$

being $A_{0}$ is maximum stress amplitude, which corresponds to the centre of the sample.

A value of $A_{0}$ equal to $100 \mathrm{MPa}$ was selected in the present study, so that the normal stress amplitude changed from $0 \mathrm{MPa}$ at the edges of the sample to $100 \mathrm{MPa}$ in the centre.

After UST the sample was sliced into 42 disks of $2.5 \mathrm{~mm}$ in thickness as also shown in Fig. 1. The mechanical properties under tension conditions for each disk and its correspondence with the oscillating stress amplitude can be found elsewhere [26]. In the present study, the parameters of microstructure and texture of ECAP nickel subjected to UST for the cross sections shown in the Fig.1b are defined by the slice numbers 1, 13, 19, and 30, which correspond to stress amplitude values of $A=0,79,98$, and $79 \mathrm{MPa}$, respectively.

The microstructure was studied on a scanning electron microscope TESCAN MIRA 3 LMH FEG equipped with an EBSD analyzer "CHANNEL 5". A rectangular grid with scan step of $100 \mathrm{~nm}$ was used. The EBSD analysis was performed for the central regions of the disks extracted from theultrasonic treated cylinder. Specimens for EBSD analysis were prepared by mechanical polishing with subsequent electromechanical polishing. Received EBSD maps were subjected to a clean-up procedure involving a grain tolerance angle of $5^{\circ}$ and a minimum grain size of 3 pixels.

The X-ray diffraction analysis was carried out using an DRON-4 apparatus. Specimens for X-ray analysis were identically prepared to the EBSD samples. The diffraction patterns were recorded with a step $0.05^{\circ}$ and exposition time $5 \mathrm{~s}$. The $\mathrm{CuK}_{\alpha}$ line was used with Bragg-Brentano focusing. A Soller collimator for primary beam and a graphite monochromator for diffracted beam were used. The experimental data were processed by means of the software «Maud» (Materials Analysis Using Difraction) [31] that uses the Rietveld method [32] in its algorithm.

\section{Experimental results}

Table 1 summarizes all experimental data obtained by microhardness measurements, X-ray analysis and EBSD analysis.

\subsection{Microhardness}

Table 1 show the evolution of microhardness $(\mathrm{Hv})$ as a function of the position on the ECAP rod treated by ultrasound and the corresponding value of the applied UST stress amplitude. It is apparent that the Hv values increase for the cross-sections corresponding to samples \#13 and \#30 
$(\mathrm{A}=80 \mathrm{MPa})$ comparing to the untreated sample $\# 1(\mathrm{~A} \approx 0 \mathrm{MPa})$ and they slightly decrease as the US amplitude increases, i.e. for the samples \#19 and \#24 (A=98 MPa).

\subsection{X-Ray analysis}

The results of the Rietveld analysis of X-ray data are presented as well in Table 1. As for microhardness similar trend was observed for crystallite size. i.e. decreases for samples \#13 and \#30 and increases for samples \#19 and \#24 in comparison with the untreated specimen \#1. Microstrain values posses a reciprocal dependence, that is, increasing for samples \#13 and \#30 and decreasing for samples \#19 \& \#24. On the other hand, dislocation density can be estimated using the following equation [33, 34]:

$$
\rho_{X R}=\frac{2 \sqrt{3<\varepsilon^{2}>}}{d b}
$$

where $\left\langle\varepsilon^{2}\right\rangle^{1 / 2}$ is the microstrain, $d$ is the crystallite size and $b=2.49 \AA$ is the Burgers vector for nickel. Dislocation density increases for the specimens subjected to UST with amplitude of 80 $\mathrm{MPa}(\# 13$ \& \#30) and decreases slightly for the specimens treated at $98 \mathrm{MPa}$.

\subsection{EBSD data}

Figure 2 represents in 3 columns (from left to right) the inverse pole figures (IPF), the Kernel average misorientation (KAM) maps and the (111) pole figures for samples \#1, 13, 19, 24 and 30. Black lines in IPF and KAM maps separate high angle boundaries (HAB), i.e. misorientation angles higher than $15^{\circ}$. Scale bars on all maps correspond to 5 micrometers. Last row in the Fig. 2 shows the legends for IPF and KAM maps and for the (111) pole figures. Sample \#1 corresponds to UST with very small amplitude ( 7.5 MPa) and shows the typilca microstructure of ECAPed materials[34]. Insets in the texture column show the texture strength. All specimens exemplified have a fairly strong texture with maxima from 8.2 times random level for the specimen \#1 up to 10.5 times random level for the specimen \#13.

Figure 3 summarizes the grain size distribution obtained by the intercept method and the grain boundary misorientation distribution (GBMD). Mean grain size of the specimens subjected to identical UST is similar: mean grain size of the sample \#19 is $0.55 \mu \mathrm{m}$ which is very close to the value of $0.54 \mu \mathrm{m}$ for the sample \#24. Likewise, the mean grain size of $0.42 \mu \mathrm{m}$ for the sample \#13 is close to the value of $0.40 \mu \mathrm{m}$ for the sample \#30. Grain boundary misorientation distributions are comparable for all specimens and they consist of large fraction of low angle boundaries (LAB). However, a careful inspection shows a slight increase in the fraction of high 
angle boundaries (HAB) with increasing amplitude of UST: samples \# 19 and 24 possess almost identical fractions of $\mathrm{HAB}$ of about $45 \%$.

Using kernel average misorientation (KAM), the dislocation density can be evaluated in turns by using the equation [35]:

$$
\rho_{E B S D}=\frac{\theta}{h D}
$$

where $\theta$ is the kernel average misorientation in radians, $h$ is a scanning step size and $D$ is a grain size, obtained using EBSD by intercepts method.

All parameters obtained by experimental measurements using EBSD are presented in Table 1.

\section{Discussion}

$X$-Ray and EBSD analysis.

Fig. 4 depicts the crystallite size and the microstrain plotted as a function of the position in the half-wave specimen, or in other words, of the US amplitude. The crystallite size decreases with increasing of US amplitude reaching the minimum of about $160 \mathrm{~nm}$ for the maximum applied UST stress. However, the microstrain behaves differently: it increases as UST amplitude increases from $0 \mathrm{MPa}$ to the value of $80 \mathrm{MPa}$ and then decreases as the US amplitude continues increasing. These results are in good accordance with data obtained earlier [36].

Fig. 5 summarizes the results of calculation of dislocation density based on X-Ray analyses and EBSD measurements. Despite of the complex shape for the microstrain, dislocation density evaluated by X-ray follows the UST amplitude. Here it is assumed that this dislocation density corresponds to stochastically stored dislocations (SSD) induced by ultrasonic treatment. Their density level is one order of magnitude lower than it is usually observed for nickel subjected to severe plastic deformation [37]. This is in good consistence with the relatively low amplitude of UST. The dislocation density evaluated from kernel average misorientation by EBSD reflects the density of geometrically necessary dislocations (GNB) and it shows the level of dislocations stored in low angle boundaries with misorientation ranging from 1 to 5 degrees.

\section{Deformation mechanisms.}

Applying two models for strain hardening, namely the Hall-Petch equation, and dislocation strengthening, one can estimate the yield strength for nickel subjected to UST as a function of US amplitude. The Hall-Petch likewise relation for microhardness is 


\section{$A C C E H_{V}=H_{V 0}^{M A}+K_{H V} / \sqrt{D}$,}

where $H_{V 0}$ is the grain size-independent microhardness due to lattice friction and other mechanisms (i.e. Orowan hardening due to impurities), $K_{H V}$ is an empirical coefficient of grainsize strengthening, and $D$ is the grain size determined by intercepts in EBSD. In ref [38] the Hall-Petch relation was studied for microhardness in ultrafine-grained and nanostructured nickel processed by different methods and from linear fitting of experimental data the following values for its parameters were calculated: $H_{\mathrm{V} 0}=833 \mathrm{MPa}$ and $K_{\mathrm{H}}=596.4 \mathrm{MPa} \cdot \mu \mathrm{m}^{1 / 2}$.

The contribution of dislocation strengthening can be also estimated from [39]

$$
H_{V D} \approx 3 \cdot \sigma_{D S}=3 \alpha M G b \sqrt{\rho}
$$

where is $\alpha=0.24$ is the numerical coefficient describing the average contribution from dislocations of different type (screw or edge), $M=3$ is the Taylor factor, $G=78.9 \mathrm{GPa}$ is the shear modulus of nickel, $b=0.249 \mathrm{~nm}$ is the Burgers vector for nickel and $\rho=\rho_{\mathrm{SD}}+\rho_{\mathrm{GNB}}$ is the total dislocation density. Fig. 6 presents the calculated microhardness as a function of the position in nickel specimen or as a function of the amplitude of applied ultrasound and experimentally measured microhardness. The calculated microhardness is in excellent agreement with experimental values corresponding to the non-treated area of the specimen and in general it follows the dependence (less than $10 \%$ of difference) of $H v$ with the position on the rod or the amplitude of ultrasonic treatment. The microhardness of the sample \#0 (ECAP area) is lower than that reported in $[39,40]$. This is due to the fact that the present specimen was processed at $350^{\circ} \mathrm{C}$ and not at room temperature.

\section{Model for microstructure evolution during UST.}

Supposedly, the influence of ultrasonic treatment (Fig. 1) is symmetrical regarding to zero point of the specimen or the maximum of US amplitude. This means that the experimental data for the samples \#13 and \#30 and for \#19 and \#24 can be averaged by pairs. Microstructural characteristics obtained by such an averaging are summarized in Table 2. It is apparent that the crystallite size decreases and stochastic dislocation density increases as ultrasonic amplitude increases from zero to the maximum of $100 \mathrm{MPa}$. Concurrently, microstructural parameters obtained using EBSD behave differently: grain size (acquired by intercepts) and GNB density decrease as US amplitude increases to the value of $80 \mathrm{MPa}$. At the central point of the specimen with the maximum of US amplitude the grain size increases again but to intermediate level of $0.55 \mu \mathrm{m}$, which is lower than one for untreated area. The GNB density returns to the level of the sample \#0. Such an evolution of microstructure on two different scale levels can allow constructing a phenomenological model for ECAP nickel subjected to ultrasonic treatment 
(Table 3). Under ultrasound conditions the structure is introduced the dislocations which are mostly stochastic in types due to alternating sign of ultrasonic impact. However, increasing in US amplitude leads to increasing the heat released during the US treatment, which consequently initiates recovery in the area of higher US amplitude.

\section{Summary}

Investigation of the structure of ECAPed nickel under a post UST shows that the relaxation effect is non-linearly dependent on the amplitude of ultrasound. The decrease of dislocation density, the low-angle grain boundary fraction and the changes in texture are most significant in the state after ECAP and UST within the amplitude of $80 \mathrm{MPa}$. With the increase of amplitude to $98 \mathrm{MPa}$ the effect is not so strong. This dependence can be explained by rearrangement of dislocations under the action of the oscillating force. When this force is low enough, the incompletely formed low-angle dislocation boundaries rearrange into the stable boundaries that do not produce long-range stresses. Also, the annihilation process takes place due to increase of dislocation mobility. But, with the increase of the US intensity the generation of new dislocations becomes possible. These two effects introduce a different contribution in the dependence of the ultrasound amplitude.

Understanding this mechanisms and their dependence of the US intensity it becomes possible to use the relaxation effect of the UST in the nanostructured materials processed by ECAP and to get desirable properties. The finding out of the optimum regimes of the UST for achieving the maximum relaxation effect without loss of strength requires further investigations.

Acknowledgments

This work was supported by the Russian Science Foundation under the grant No. 16-19-10129.

References:

1. Severdenko, V.P., Klubivich V.V., and Stepanenko, A.V., Metal Forming with Ultrasound (Nauka I Tekhnika, Minsk, 1973) (In Russian).

2. Kulemin, A.V., Ultrasound and Diffusion, Metallugia Publ., Moscow, 1978 (In Russian).

3. Markov, A.I., Ultrasonic Treatment of Materials, Machine Building Publ., Moscow, 1980 (In Russian).

4. Abramov, O.V., High-Intensity Ultrasonics: Theory and Industrial Applications, CRC Press, Boca Raton, 1999. 
5. Tyapunina NA, NaimiEK, Zinenkova GM, Ultrasound Action on Crystals with Defects. Moscow: Moscow State Univ. 1999, 238p. (in Russian)

6. Craff, K., Ultrasonic metal welding, In: New developments in advanced welding (Ed. Ahmed N). Cambridge: Woodhead Publ, 2005, p. 241-269.

7. Power Ultrasonics. Applications of High-Intensity Ultrasound, Juan A. Gallego-Juárez \& Karl F. Graff, (Editors), Woodhead Publishing, 2014, 1166 p.

8. Blaha F, Langenecker B. (1955) Dehnung von Zink-Kristallen unter Ultraschalleinwirkung. Naturwissenschaften 42(20):556.

9. Archbutt L. (1921) Failure of the lead sheathing of electric cables. Trans Faraday Soc $17: 22-35$.

10. Yasuoka M., Wang P., Zhang K., Qiu Z., Kusaka K., Pyoun Y.-S., Murakami R. Improvement of the fatigue strength of SUS304 austenite stainless steel using ultrasonic nanocrystal surface modification, Surface and Coating Technology 218 (2013) 93-98. http://dx.doi.org/10.1016/j.surfcoat.2012.12.033

11. B.N. Mordyuk, G.I. Prokopenko, Ultrasonic impact peening for the surface properties' management, J. Sound Vibr. 308 (2007) 855-866. http://dx.doi.org/10.1016/j.jsv.2007.03.054

12. Roy S, Fisher J, Yen B. (2003) Fatigue resistance of welded details enhanced by ultrasonic impact treatment (UIT). Intern Journ Fatigue 25(9-11):1239-1247.

13. Abramov VO, Abramov OV, Sommer F, Gradov OM, Smirnov OM. (1998) Surface hardening of metals by ultrasonically accelerated small metal balls. Ultrasonics 36:10131019.

14. S. Belyaev, A. Volkov, N. Resnina, Alternate stresses and temperature variation as factors of influence of ultrasonic vibration on mechanical and functional properties of shape memory alloys, Ultrasonics 54 (2014) 84-89.

15. V.V. Rubanik Jr., V.V. Rubanik, V.V. Klubovich, The influence of ultrasound on shape memory behavior, Mater. Sci. Eng. A, 481-482 (2008) 620-622. http://dx.doi.org/10.1016/j.msea.2007.02.134.

16. Lotkov, A.I., Baturin, A.A., Grishkov, V.N., Kovalevskaya, Zh.G., Kuznetsov, P.V., Effect of ultrasonic plastic treatment on the surface structure and phase state of nickel titanium, Techn. Phys. Lett. 31 (11) (2005) 912-914. http://dx.doi.org/10.1134/1.2136950.

17. Valiev RZ, Zhilyaev AP, Langdon TG. Bulk nanostructured materials: fundamentals and applications. NewJersey: Wiley, 2014, 450p. 
18. Nazarov AA, Mulyukov RR. In: Handbook of Nanoscience, Engineering, and Technology, edited by W. Goddard, D. Brenner, S. Lyshevski, and G. Iafrate (Boca Raton: CRC Press, 2002), p.22-1.

19. Zhao YH, Liao XZ, Horita Z, Langdon TG, Zhu YT. (2008) Determining the optimal stacking fault energy for achieving high ductility in ultrafine-grained $\mathrm{Cu}-\mathrm{Zn}$ alloys. Mater Sci Eng A 493(1-2):123-129.

20. Ni S, Wang YB, Liao XZ, Alhajeri SN, Li HQ, Zhao YH, Lavernia EJ, Ringer SP, Langdon TG, Zhu YT. (2011) Grain growth and dislocation density evolution in a nanocrystalline Ni-Fe alloy induced by high-pressure torsion. Scripta Mater 64(4):327330.

21. Zhao YH, Liao XZ, Jin Z, Valiev RZ, Zhu YT. (2004) Microstructures and mechanical properties of ultrafine grained $7075 \mathrm{Al}$ alloy processed by ECAP and their evolutions during annealing. Acta Mater 52(15):4589-4599.

22. Zhilyaev AP, Nurislamova GV, Baro MD, Valiev RZ, Langdon TG. (2002) Thermal stability and microstructural evolution in ultrafine-grained nickel after equal-channel angular pressing (ECAP). Metall Mater Trans A 33(6):1865-1868.

23. Nazarov, A.A., Khannanov, Sh.Kh., Ultrasonic Stimulation of Polygonization Process, Fiz. Khim. Obrab. Mater., No. 4, 109-114 (1986) (In Russian).

24. Bushueva GV, Zinenkova GM, Tyapunina NA, Degtyarev VT, Losev AYu, Plotnikov FA. (2008) Self-organization of dislocations in an ultrasound field. Crystal Rep 53(3):474-479.

25. Nazarova AA, Mulyukov RR, Rubanik VV, Tsarenko YuV, Nazarov AA. (2010) Effect of ultrasonic treatment on the structure and properties of ultrafine-grained nickel. Phys Metals Metallogr 110(6):574-581.

26. Samigullina AA, Nazarov AA, Mulyukov RR, Tsarenko YuV, Rubanik VV. (2014) Effect of Ultrasonic Treatment on the Strength and Ductility of Bulk Nanostructured Nickel Processed by Equal-channel Angular Pressing. Rev Adv Mater Sci 39(1):48-53.

27. Samigullina AA, Mulyukov RR, Nazarov AA, Mukhametgalina AA, Tsarenko YuV, Rubanik VV. (2014) The increase of impact strength of ultrafine grained nickel after ultrasonic treatment. Lett Mater 4(1):52-54.

28. Nazarova AA, Dmitriev SV, Baimova YuA, Mulyukov RR, Nazarov AA. (2011) Computer simulation of the effect of ultrasound and annealing on the structure of a twodimensional severely deformed nanocrystalline material. Phys Metals Metallog 111:513.

29. Nazarov, A.A., Molecular dynamics simulation of the relaxation of a grain boundary disclination dipole under ultrasonic stresses, Letters on Materials 6 (3) (2016) 179-182. http://dx.doi.org/10.22226/2410-3535-2016-3-179-182. 
30. Nazarov, A.A., Molecular dynamics simulation of the effect of ultrasonic vibrations on the structure of nonequilibrium [112] tilt grain boundaries in nickel, Rev. Adv. Mater. Sci. 47 (2016) 42.

31. Lutterotti, L., Maud - Materials Analysis Using Diffraction, http://www.ing.unitn.it/ maud.

32. Rietveld HM. (1969)A profile refinement method for nuclear and magnetic structures. J Appl Crystall 2(2):65-71.

33. Williamson GK, Smallman RE. (1956) III. Dislocation densities in some annealed and cold-worked metals from measurements on the X-ray debye-scherrer spectrum. Philos Mag $1: 34-46$

34. Beyerlein IJ, Tóth LS. (2009) Texture evolution in equal-channel angular extrusion. Prog Mater Sci 54:427-510.

35. Zhilyaev AP, Morozova A, Cabrera JM, Kaibyshev R, Langdon TG. (2017) Wear resistance and electroconductivity in a $\mathrm{Cu}-0.3 \mathrm{Cr}-0.5 \mathrm{Zr}$ alloy processed by ECAP. J Mater Sci 52(1):305-313.

36. Samigullina AA, Tsarenko YV, Rubanik VV, Popov VA, Danilenko VN, Mulyukov RR. (2012) Effect of ultrasonic treatment on structure and mechanical properties of ultrafinegrained nickel processed by equal-channel angular pressing. Lett Mater 2(4):214-217.

37. Zhilyaev AP, Baró MD, Langdon TG, McNelley TR. An examination of microtexture and microstructure in ultrafine-grained nickel. Rev. Adv. Mater. Sci. 2004; 7(1):41-49.

38. Zhilyaev AP, Gimazov AA, Soshnikova EP, Révész A, Langdon TG. (2008) Microstructural characteristics of nickel processed to ultrahigh strains by high-pressure torsion. Mater Sci Eng A 489(1-2):207-212.

39. Krasilnikov N, Lojkowski W, Pakiela Z, Valiev R. (2005) Tensile strength and ductility of ultrafine-grained nickel processed by severe plastic deformation. Mater Sci Eng A 397:330-337.

40. Naidenkin EV, Ivanov KV, Golosov EV. (2014) Effect of cryorolling on the structure and the mechanical properties of ultrafine grained nickel. Russ Metall (Metally) 4:303-307. 


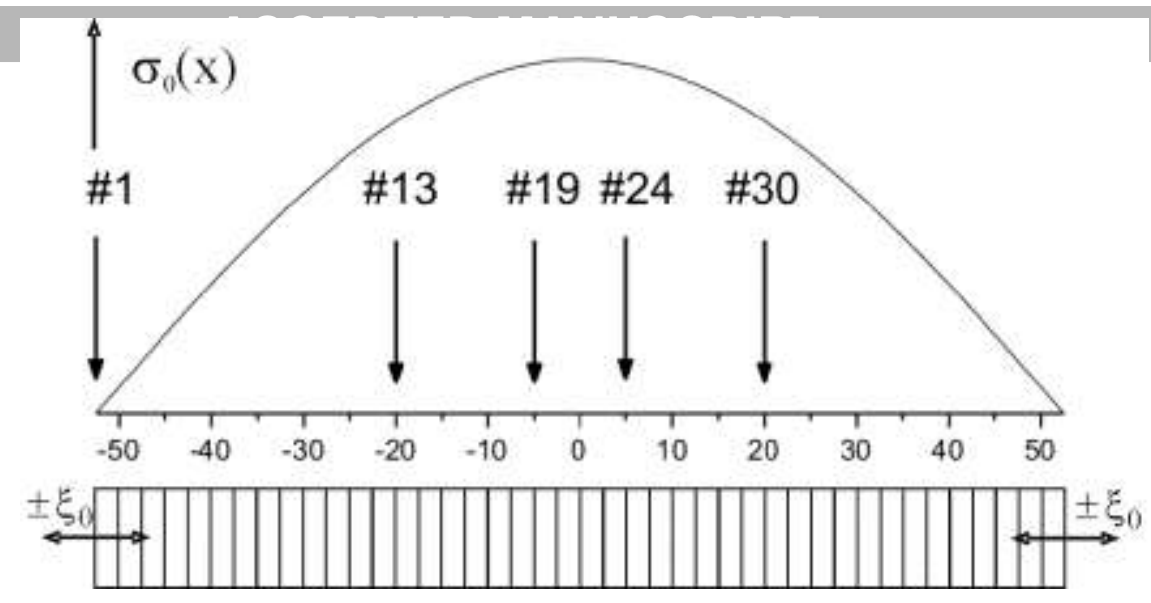

Fig. 1. Schematic of the sample and US amplitude distribution. 


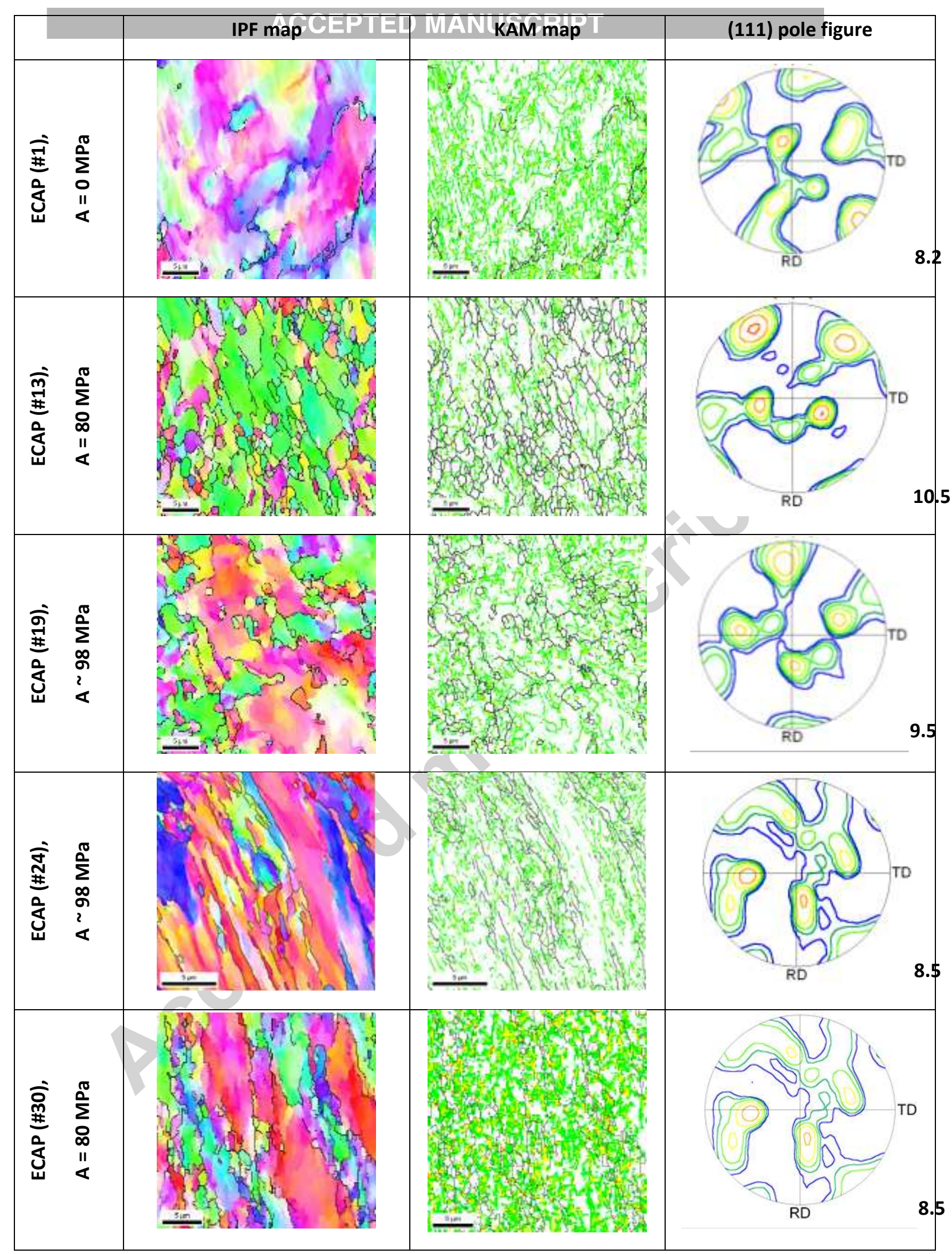




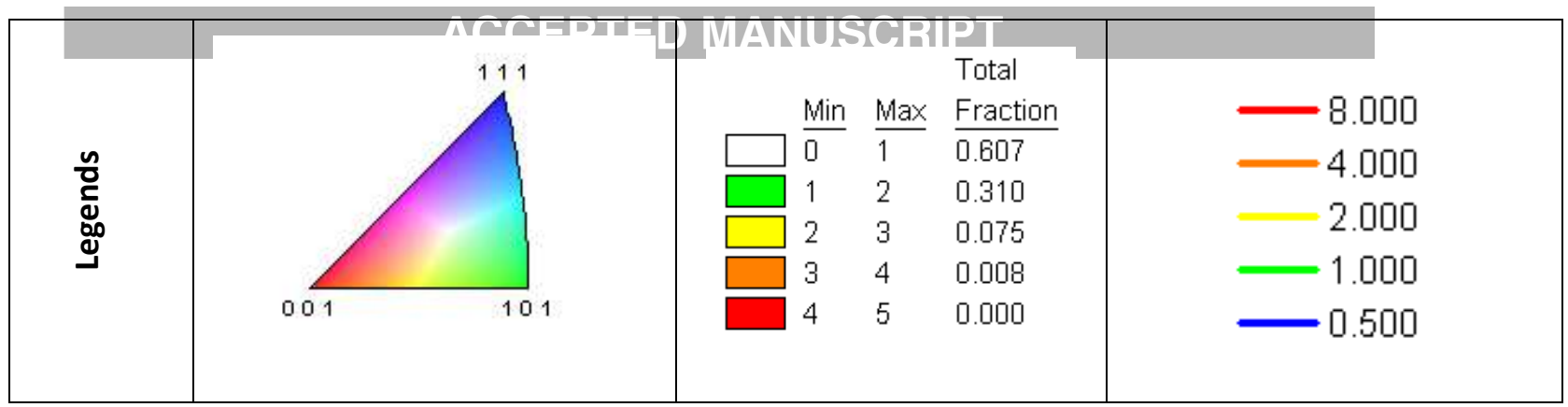

Fig. 2. IPF and KAM maps, (111) pole figures for different cross sections of ECAP nickel subjected to ultrasonic treatment.

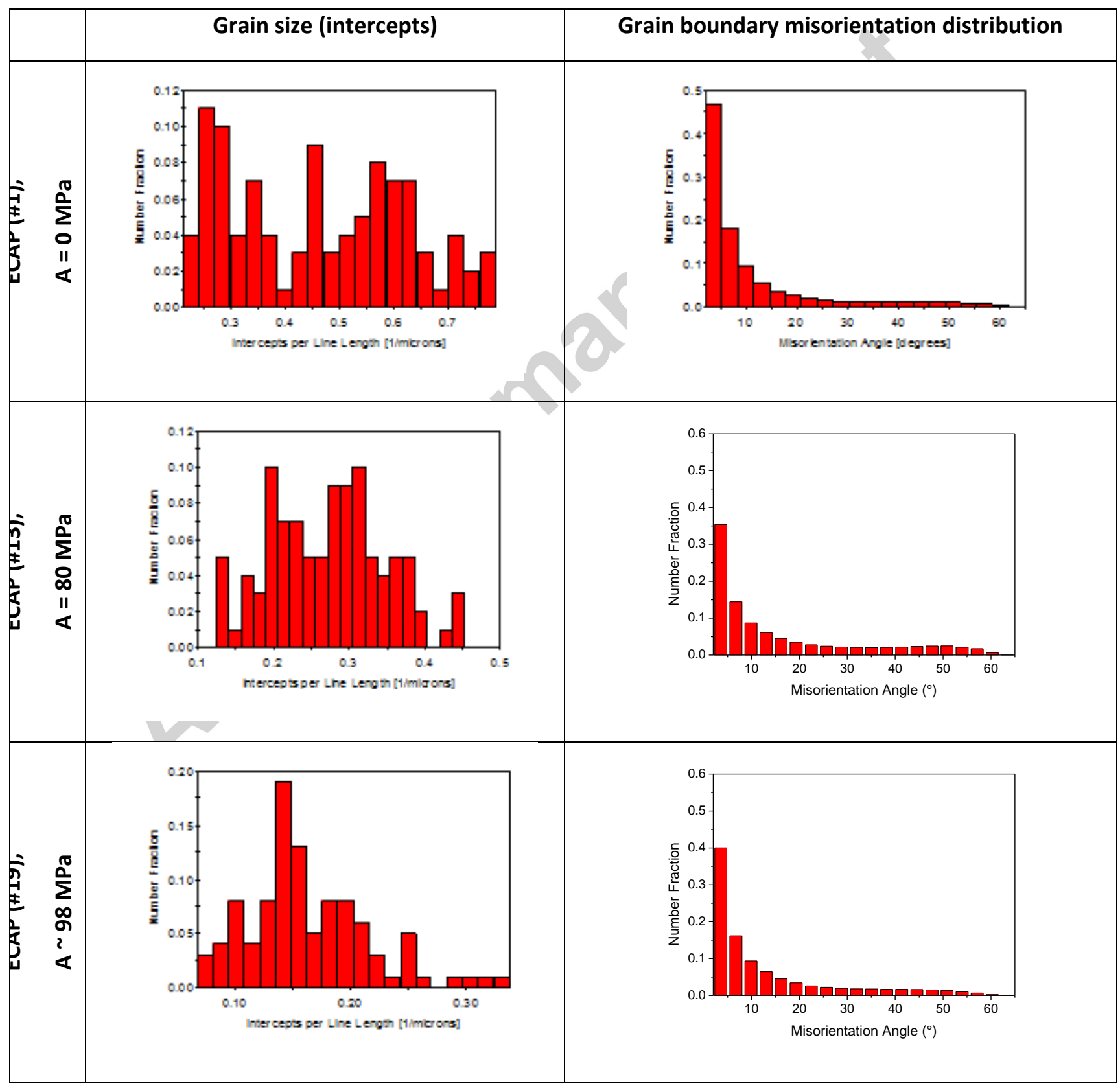




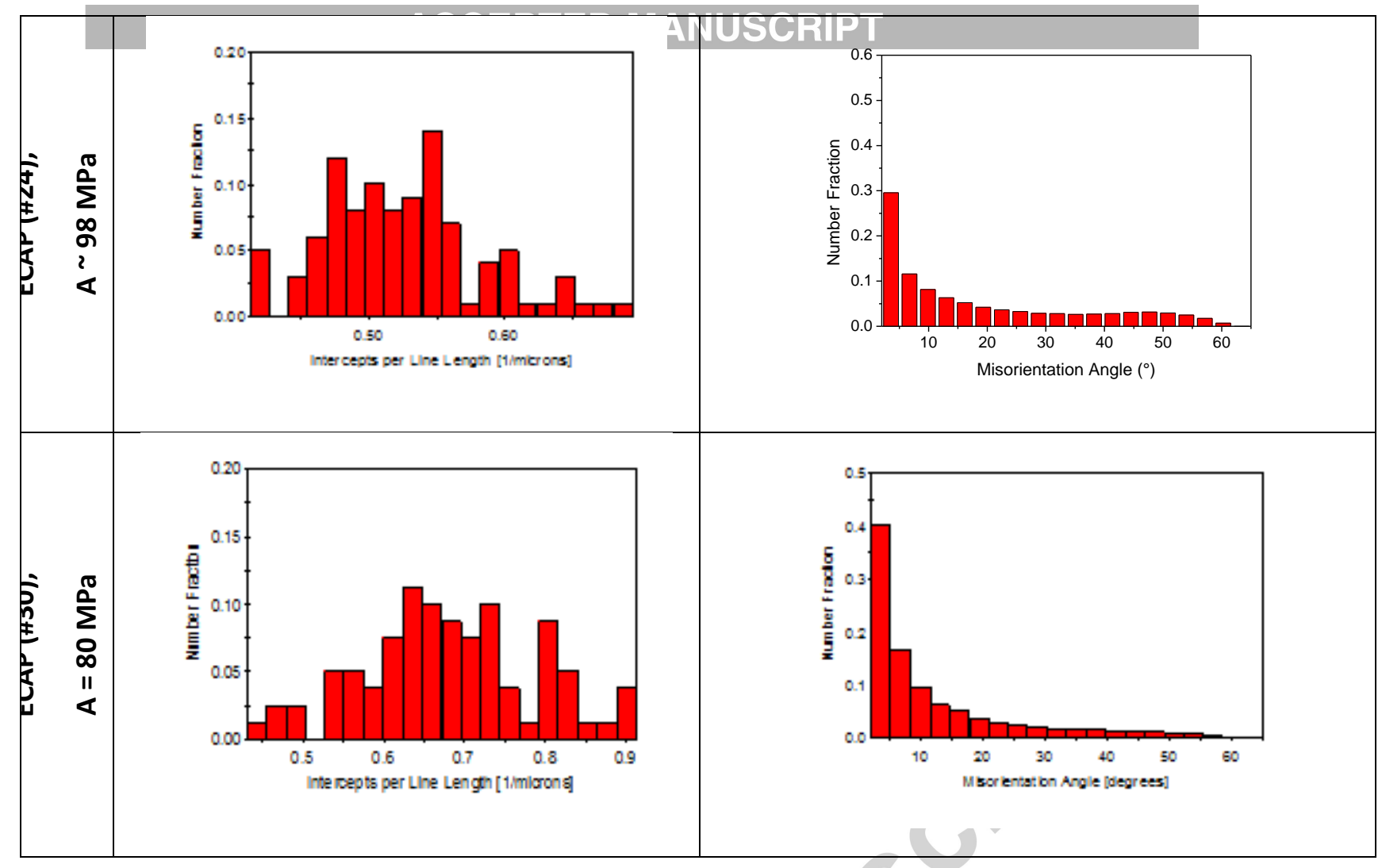

Fig. 3. Grain size distribution (by intercepts) and Grain boundary misorientation distribution in ECAP nickel specimens subjected to ultrasonic treatment

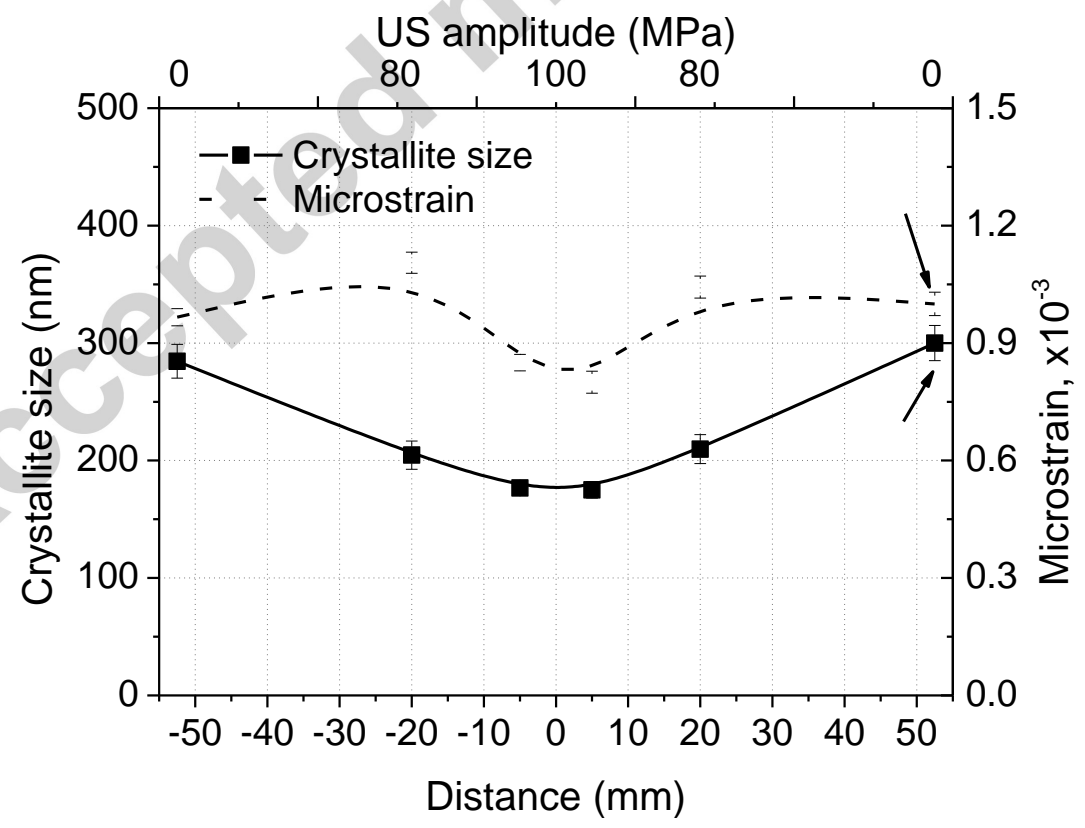

Fig. 4. Microcrystallite size and microstrain by X-Ray analysis of ECAP nickel specimens subjected to ultrasonic treatment. Arrows indicates data points interpolated. 


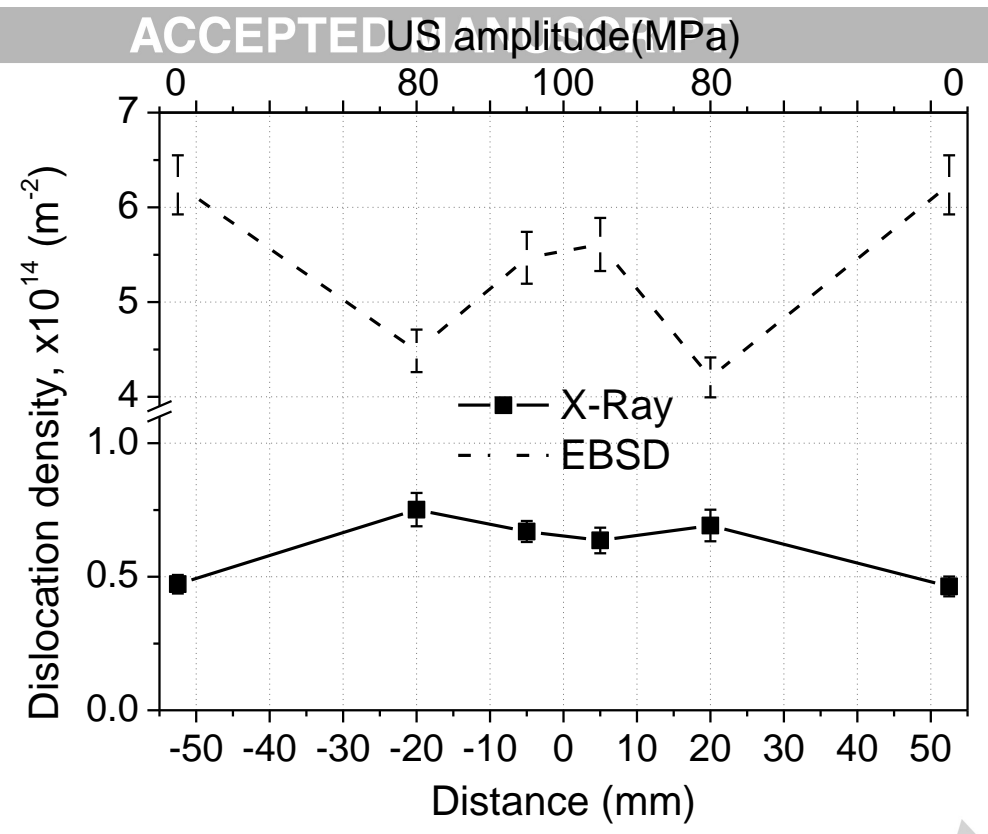

Fig. 5. Dislocation density calculated by X-Ray and EBSD analysis of ECAP nickel specimens subjected to ultrasonic treatment.

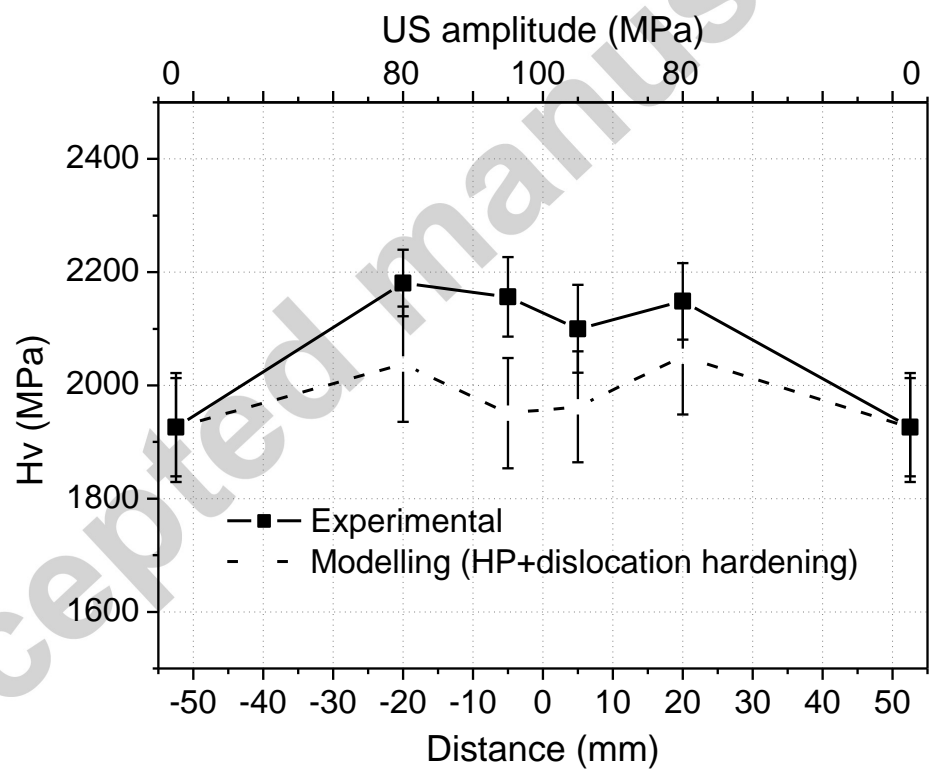

Fig. 6. Experimental and calculated microhardness of ECAP nickel subjected to UST. 
Table 1. Microhardness and microstructural parameters by X-ray and EBSD analyses

\begin{tabular}{|c|c|c|c|c|c|c|c|c|c|c|}
\hline \multirow[b]{2}{*}{$\begin{array}{l}\text { Speci } \\
\text { men }\end{array}$} & \multirow[b]{2}{*}{$\begin{array}{l}\text { Positi } \\
\text { on } \\
\text { (mm) }\end{array}$} & \multirow[b]{2}{*}{$\begin{array}{c}\text { Ultras } \\
\text { onic } \\
\text { amplit } \\
\text { ude } \\
\text { (MPa) }\end{array}$} & \multirow[b]{2}{*}{$\begin{array}{c}\mathrm{Hv} \\
(\mathrm{MPa})\end{array}$} & \multicolumn{3}{|c|}{ X-ray } & \multicolumn{4}{|c|}{ EBSD } \\
\hline & & & & $\begin{array}{c}\text { Crystall } \\
\text { ite size, } \\
d(\mathrm{~nm})\end{array}$ & $\begin{array}{c}\text { Microstr } \\
\text { ain, } \\
\left\langle\varepsilon^{2}\right\rangle^{1 / 2} \\
\times 10^{-3}\end{array}$ & $\begin{array}{c}\text { Disloca } \\
\text { tion } \\
\text { density } \\
, \rho_{x-\text { ray, }} \\
\times 10^{14} \\
\left(\mathrm{~m}^{-2}\right) \\
\end{array}$ & $\begin{array}{c}\text { Ste } \\
p \\
\text { siz } \\
e \\
\text { (n } \\
m \text { ) }\end{array}$ & $\begin{array}{l}\mathrm{KA} \\
\mathrm{M} \\
\left({ }^{\circ}\right)\end{array}$ & $\begin{array}{c}\text { Grain } \\
\text { size by } \\
\text { interce } \\
\text { pts } \\
(\mu \mathrm{m})\end{array}$ & $\begin{array}{c}\text { Disloca } \\
\text { tion } \\
\text { density } \\
, \rho_{\text {EBSD }} \\
\times 10^{14} \\
\left(\mathrm{~m}^{-2}\right) \\
\end{array}$ \\
\hline \#1 & -52.5 & 0 & $\begin{array}{c}1926.2 \pm \\
86.9\end{array}$ & $\begin{array}{c}284.5 \pm \\
14.4\end{array}$ & $\begin{array}{c}0.966 \pm 0 \\
022\end{array}$ & $\begin{array}{c}0.47 \pm 0 . \\
04\end{array}$ & $\begin{array}{c}10 \\
0\end{array}$ & $\begin{array}{c}0.8 \\
9\end{array}$ & $\begin{array}{c}0.62 \pm 0 \\
.03\end{array}$ & $\begin{array}{c}6.24 \pm 0 . \\
62\end{array}$ \\
\hline$\# 13$ & -20 & 80 & $\begin{array}{c}2180.7 \pm \\
58.7\end{array}$ & $\begin{array}{c}204.6 \pm \\
12.0\end{array}$ & $\begin{array}{c}1.105 \pm 0 \\
027\end{array}$ & $\begin{array}{c}0.75 \pm 0 . \\
06\end{array}$ & $\begin{array}{c}10 \\
0\end{array}$ & $\begin{array}{c}0.6 \\
4\end{array}$ & $\begin{array}{c}0.42 \pm 0 \\
.02\end{array}$ & $\begin{array}{c}4.49 \pm 0 . \\
45\end{array}$ \\
\hline$\# 19$ & -5 & 98 & $\begin{array}{c}2156.2 \pm \\
70.2\end{array}$ & $\begin{array}{c}176.6 \pm \\
6.0\end{array}$ & $\begin{array}{c}0.850 \pm 0 \\
021\end{array}$ & $\begin{array}{c}0.67 \pm 0 . \\
04\end{array}$ & $\begin{array}{c}10 \\
0\end{array}$ & $\begin{array}{c}0.7 \\
8\end{array}$ & $\begin{array}{c}0.55 \pm 0 \\
.02\end{array}$ & $\begin{array}{c}5.61 \pm 0 . \\
56\end{array}$ \\
\hline$\# 24$ & 5 & 98 & $\begin{array}{c}2148.6 \pm \\
67.5\end{array}$ & $\begin{array}{c}175.4 \pm \\
6.8\end{array}$ & $\begin{array}{c}0.800 \pm 0 \\
028\end{array}$ & $\begin{array}{c}0.64 \pm 0 . \\
05\end{array}$ & $\begin{array}{c}10 \\
0\end{array}$ & $\begin{array}{c}0.9 \\
8\end{array}$ & $\begin{array}{c}0.54 \pm 0 \\
.02\end{array}$ & $\begin{array}{c}6.87 \pm 0 . \\
69\end{array}$ \\
\hline$\# 30$ & 20 & 80 & $\begin{array}{c}2202.0 \pm \\
87.7\end{array}$ & $\begin{array}{c}209.7 \pm \\
12.3\end{array}$ & $\begin{array}{c}1.043 \pm 0 \\
028\end{array}$ & $\begin{array}{c}0.69 \pm 0 . \\
06\end{array}$ & $\begin{array}{c}20 \\
0\end{array}$ & $\begin{array}{c}1.2 \\
0\end{array}$ & $\begin{array}{c}0.40 \pm 0 \\
.02\end{array}$ & $\begin{array}{c}4.21 \pm 0 . \\
42\end{array}$ \\
\hline$\# 41$ & 52.5 & 0 & $\begin{array}{c}1926.2 \pm \\
86.9\end{array}$ & $\begin{array}{c}300.0 \pm \\
15.0\end{array}$ & $\begin{array}{c}1.000 \pm 0 \\
03\end{array}$ & $\begin{array}{c}0.46 \pm 0 . \\
04\end{array}$ & $\begin{array}{c}10 \\
0\end{array}$ & $\begin{array}{c}0.8 \\
9\end{array}$ & $\begin{array}{c}0.62 \pm 0 \\
.03\end{array}$ & $\begin{array}{c}6.24 \pm 0 . \\
62\end{array}$ \\
\hline
\end{tabular}


Table 2. Microstructure parameters of the ECAP nickel subjected to ultrasonic treatment

\begin{tabular}{ccccc}
\hline US amplitude & \multicolumn{2}{c}{ X-ray } & \multicolumn{2}{c}{ EBSD } \\
\cline { 2 - 5 }$(\mathrm{MPa})$ & Crystallite size $(\mathrm{nm})$ & $\mathrm{SD}, \times 10^{14}\left(\mathrm{~m}^{-2}\right)$ & Grain size $(\mu \mathrm{m})$ & $\mathrm{GNB}, \times 10^{14}\left(\mathrm{~m}^{-2}\right)$ \\
\hline 0 & $284.5 \pm 14.4$ & $0.47 \pm 0.04$ & $0.62 \pm 0.03$ & $6.24 \pm 0.62$ \\
80 & $232.2 \pm 12.3$ & $0.66 \pm 0.04$ & $0.41 \pm 0.02$ & $4.35 \pm 0.43$ \\
98 & $168.0 \pm 5.9$ & $0.79 \pm 0.06$ & $0.55 \pm 0.03$ & $6.24 \pm 0.62$ \\
\hline
\end{tabular}

Table 3. Schematic of microstructure evolution of the ECAP nickel subjected to ultrasonic treatment.

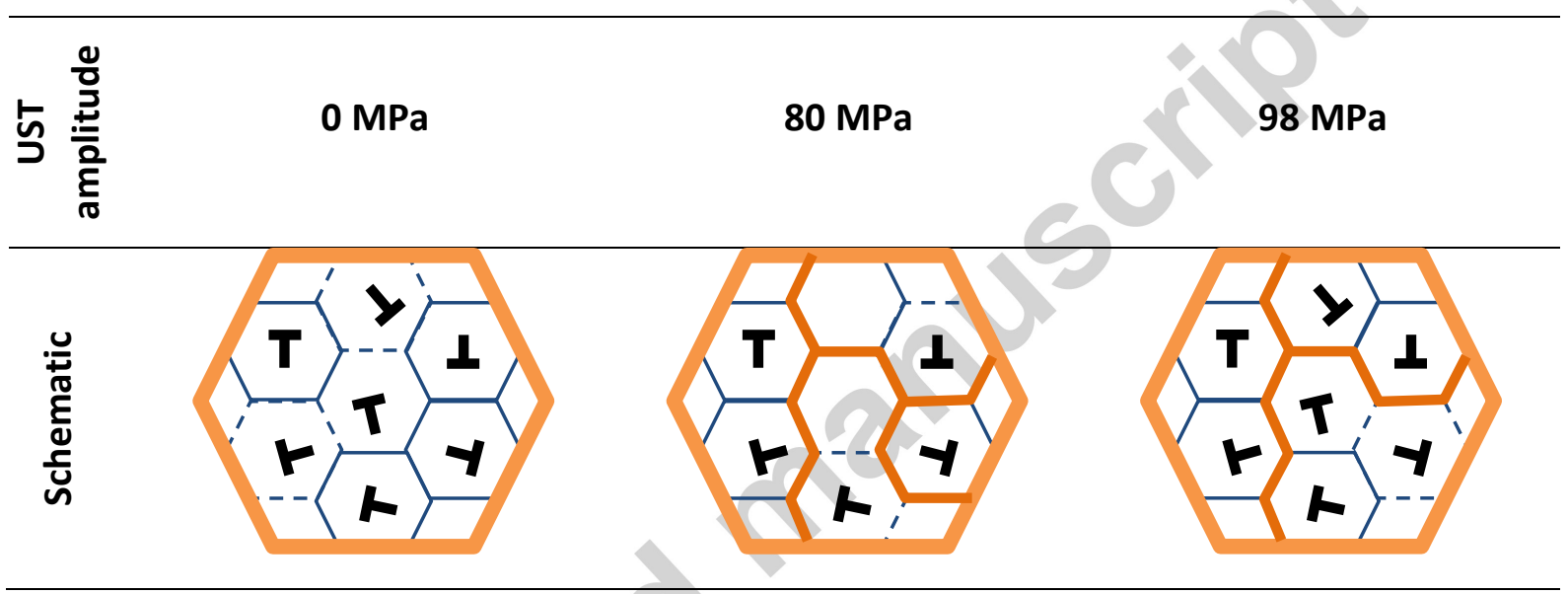

